\title{
Meningkatkan pengetahuan dan sikap ibu hamil tentang kepatuhan konsumsi tablet Fe melalui media visual
}

\author{
Tri Siswati*, Savitri Fatikaningtyas, Made Alit Gunawan
}

Jurusan Gizi, Poltekkes Kemenkes Yogyakarta, Jalan Tata Bumi No.3 Banyuraden, Sleman, 55143

trisiswati14@gmail.com*

\begin{tabular}{ll}
\hline \multicolumn{2}{l}{ Informasi artikel: } \\
\hline Diterima & $: 5$ Maret 2021 \\
Revisi & $: 15$ Maret2021 \\
Terbit & $: 28$ April 2021
\end{tabular}

PBSTRAK meningkatkan pengetahuan dan sikap melalui berbagai program, salah satunya pengembangan media komunikasi, informasi, dan edukasi (KIE). Penelitian ini bertujuan untuk mengetahui perbedaan efektivitas booklet

\section{Key word:}

Knowledge

Attitude

Anemia

Booklet

Leaflet

\section{Kata kunci:}

Pengetahuan

Perilaku

Anemia

Booklet

Leaflet

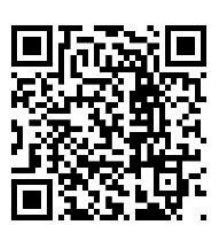
dan leaflet anemia terhadap peningkatan pengetahuan tentang anemia dan sikap dalam mengkonsumsi tablet besi pada ibu hamil. Penelitian ini merupakan penelitian eksperimen semu dengan desain pretest-posttest control group design. Pengambilan data dilakukan pada bulan Maret 2020 di Puskesmas Tempel I dan Puskesmas Kalasan Kabupaten Sleman DIY. Subjek dipilih secara purposive. Kelompok intervensi booklet adalah Puskesmas Tempel I dan kelompok kontrol/kelompok intervensi leaflet adalah Puskesmas Kalasan dengan subyek masing-masing 32 orang. Pengumpulan data dilakukan melalui google form setelah mendapatkan persetujuan etik. Data dianalisis dengan Uji Mann-Whitney. Intervensi booklet meningkatkan pengetahuan ibu sebesar 3,1 sedangkan leaflet sebesar 2,4 tidak ada perbedaan yang signifikan. Intervensi dengan booklet meningkatkan sikap ibu tentang kepatuhan Fe sebesar 4,7 dan leaflet sebesar 1 dan terdapat perbedaan yang signifikan (0,002). Booklet lebih efektif untuk meningkatkan pengetahuan tentang anemia dan sikap konsumsi tablet zat besi pada ibu hamil dibandingkan leaflet.

\section{Increase knowledge and attitudes of pregnant women about compliance} with Fe tablet consumption through visual media

Prevention and control of anemia can be started by increasing knowledge and attitudes through various programs, one of which is the development of communication, information, and education (IEC) media. This research to determine the differences in the effectiveness of anemia booklets and leaflets on increasing knowledge about anemia and attitudes in consuming iron tablets in the pregnant women. This study was a quasi-experimental with a pretest-posttest control group design. Data were collected in March 2020 at the Tempel I Health Center and Kalasan Health Center, Sleman Regency, DIY. Subjects were selected purposively. The booklet intervention group was the Tempel I Public Health Centre and the control group/leaflet intervention group was the Kalasan Public Health Centre with 32 subjects each. Data was collected through a google form after obtaining ethic approved. Data were analyzed by Mann-Whitney Test. Booklet intervention increased mother's knowledge by 3.1 while leaflet by 2.4 there was no significant difference. Intervention with booklet increased mother's attitude about Fe adherence by 4.7 and leaflet by 1 and there was a significant difference (0.002). Booklets are more effective to increase the knowledge about anemia and attitude of consuming iron tablets in pregnant women than leaflets.

This is an open access article under the CC-BY-SA license. 


\section{Pendahuluan}

Anemia pada ibu hamil adalah salah satu masalah kesehatan global. WHO memperkirakan sebanyak 40\% ibu hamil di dunia menderita anemia. ${ }^{1}$ Menurut Riskesdas tahun 2018, prevalensi anemia ibu hamil di Indonesia lebih tinggi daripada estimasi WHO, yakni sebesar $48,9 \%$. Artinya 1 dari 2 ibu hamil di Indonesia menderita anemia. ${ }^{2}$ Sementara menurut Profil Kesehatan DIY tahun 2019 jumlah ibu hamil yang anemi lebih rendah daripada angka nasional, yaitu sebanyak $15,69 \% .^{3}$

Beberapa penyebab anemi pada ibu hamil antara lain anemia pada masa remaja 4 , defisiensi Fe, asam folat, vitamin B12 dan beberapa penyebab lainnya seperti hemoglobinopati, penyakit infeksi seperti malaria, TB, HIV dan infeksi parasit. ${ }^{1}$ Mengecah dan menanggulangi anemia pada masa kehamilan sangat utama, karena kehamilan dengan anemia dapat mengakibatkan kematian pada ibu dan anak, intra uterine growth retardation (IUGR), premature, BBLR, lahir pendek, anemia pada masa bayi dan periode kehidupan selanjutnya ${ }^{1,5}$.

Beberapa faktor yang memengaruhi terjadinya anemia pada saat kehamilan, antara lain adalah tingkat pendidikan, status ekonomi, dan kepatuhan konsumsi tablet besi. ${ }^{1,5,6}$ Sementara itu kepatuhan konsumsi tablet besi pada ibu hamil dipengaruhi oleh tingkat pengetahuan ${ }^{5,6}$, efek samping gastrointestinal akibat konsumdi $\mathrm{Fe}$, persediaan tablet yang tidak memadai (termasuk sumber daya yang terbatas untuk membeli tablet), konseling pasien yang tidak memadai oleh penyedia layanan kesehatan mengenai kegunaan tablet dan kemungkinan efek samping sementara, pemanfaatan layanan kesehatan prenatal yang buruk, ketakutan pasien tentang tablet dan kepercayaan masyarakat, sikap dan praktik yang memengaruhi persepsi wanita tentang penggunaan tablet $\mathrm{Fe}^{7}$

Beberapa program pencegahan dan penanggulangan anemia telah dilakukan oleh Dinas Kesehatan Kabupaten Sleman, seperti pemberian tablet tambah darah pada remaja, ibu hamil dan program inovasi "Getar Thala" (gerakan tanggulangi anemia remaja dan thalasemia), serta edukasi tentang pentingnya makanan bergizi dan minum tablet besi pada ibu hamil yang berkunjung pertama kali di puskesmas sesuai program nasional. ${ }^{8}$ Beberapa penelitia sebelumnya telah membuktikan bahwa media cetak seperti booklet, leaflet, poster efektif untuk sebagai alat bantu komunikasi, informasi dan edukasi (KIE) kepada masyarakat ${ }^{9-11}$. Penelitian ini dilakukan untuk mendukung hasil penelitian sebelumnya dengan membuktikan efektivitas media booklet dan leaflet sebagai media edukasi untuk meningkatkan pengetahuan tentang anemia dan sikap dalam mengkonsumsi tablet besi pada ibu hamil.

\section{Metode}

Jenis penelitian ini adalah eksperimen semu dengan pretest-posttest control group design. Penelitian ini dilakukan di wilayah kerja Puskesmas Tempel I sebagai kelompok intervensi booklet dan Puskesmas Kalasan sebagai kelompok intervensi leaflet, Kabupaten Sleman, Provinsi DI Yogyakarta dengan alasan prevalensi anemi kedua wilayah tersebut diatas prevalensi anemi di Kab Sleman. Data dikumpulkan pada bulan Maret 2021 dengan cara mengirimkan Goegle Form melalui grup WhatsApp. Penentuan subyek penelitian dilakukan dengan cara purposive sampling, dengan kriteria ibu hamil yang tinggal di wilayah Puskesmas Tempel I dan Kalasan Kab Sleman, bersedia menjadi subyek penelitian dan tidak mempunyai penyakit kronis yang memberatkan ibu hamil dalam penelitian ini, dengan subyek penelitian masing-masing kelompok 32 orang. Kelompok perlakuan (booklet) adalah ibu hamil di wilayah kerja Puskesmas Tempel I dan kelompok kontrol (leaflet) adalah ibu hamil di wilayah kerja Puskesmas Kalasan. Variabel bebas dalam penelitian ini adalah intervensi dengan booklet dan leaflet sedangkan untuk variabel terikat adalah pengetahuan ibu hamil tentang anemia dan 
sikap ibu hamil dalam mengonsumsi tablet besi. Pada masa pandemic Covid-19, seluruh kegiatan pegumpulan data dilaksanakan melalui grup WhatsApp. Peneliti memberikan penjelasan tiap materi voice note yang dikirim ke grup WhatsApp. Prepost diberikan pada hari pertama, intervensi diberikan pada hari kedua, dan posttest diberikan pada hari ke 7 . Analisis data dilakukan dengan menggunakan uji Mann-Whitney test dengan SPSS.

\section{Hasil dan Pembahasan}

a. Karakteristik Responden

Sebagian besar responden pada kelompok perlakuan adalah usia 21-30 tahun (65,6\%), pendidikan SLTA $(62,5 \%)$, tidak bekerja/Ibu rumah tangga $(56,2 \%)$ dan mempunyai kehamilan pertama (50\%), sedangkan pad akelompok kontrol sebagian besar adalah usia 2130 tahun $(84,4 \%)$, pendidikan PT $(62,5 \%)$, karyawan swasta/wiraswasta $(43,8 \%)$ dan kehamilan pertama $(71,9 \%)$.

Tabel 1. Distribusi Karakteristik Responden

\begin{tabular}{lcccc}
\hline \begin{tabular}{l} 
Karakteristik \\
\multicolumn{1}{c}{ Responden }
\end{tabular} & Jumlah & \% & Jumlah & \%o \\
\hline Usia (tahun) & & & & \\
$<21$ & 4 & 12,5 & 0 & 0 \\
$21-30$ & 7 & 65,6 & 27 & 84,4 \\
$31-40$ & 21,9 & 5 & 15,6 \\
Pendidikan terakhir & 2 & 6,3 & 1 & 3,1 \\
SLTP & 20 & 62,5 & 11 & 34,4 \\
SLTA & 10 & 31,3 & 20 & 62,5 \\
Perguruan Tinggi & & & & \\
Pekerjaan & 4 & 12,5 & 5 & 15,2 \\
PNS & 10 & 31,3 & 14 & 43,8 \\
Karyawan & & & & \\
Swasta/Wiraswasta & 18 & 56,2 & 13 & 41,0 \\
Ibu rumah tangga & & & & \\
Kehamilan & 16 & 50,0 & 23 & 71,9 \\
Kehamilan ke 1 & 15 & 46,9 & 6 & 18,8 \\
Kehamilan ke 2 & 1 & 3,1 & 3 & 9,4 \\
Kehamilan ke 3\&4 & & &
\end{tabular}

Hasil penelitian ini menyatakan kedua kelompok mengalami peningkatan pengetahuan dan sikap, namun peningkatan pengetahuan lebih tinggi pada kelompok perlakuan daripada kelompok kontrol. Hasil analisis statistis menunjukkan bahwa hanya peningkatan sikap yang menunjukkan perbedaan yang bermakna pada kedua perlakuan tersebut.

Pendidikan kesehatan merupakan proses untuk mentransfer pengetahuan dan ketrampilan untuk meningkatkan derajat kesehatan individu dan masyarakat. ${ }^{10}$ Pada penelitian ini peningkatan pengetahuan pada kelompok intervensi dengan booklet lebih tinggi daripada kelompok kontrol, namun tidak ada perbedaan yang bermakna secara statistic $(\mathrm{p}=0,726)$ (tabel 2). Sejalan dengan penelitian Yuliastuti (2019) yang menyatakan bahwa tidak ada perbedaan yang signifikan antara media booklet dan leaflet terhadap pengetahuan 
$(\mathrm{p}=0,219)^{12}$, serta Pratiwi dan Puspitasari $(2017)^{13}$. Tidak adanya perbedaan pemberian penyuluhan menggunakan booklet dan leaflet anemia terhadap pengetahuan responden dikarenakan kedua media tersebut adalah sama-sama media cetak yang berisi tulisan atau katakata. Sesuai dengan teori yang dikemukakan oleh Edgar Dale dalam Notoadmodjo (2007) yang menjelaskan bahwa dalam menyampaikan informasi dapat memanfaatkan media sebagai alat bantu. Tingkat intensitas alat bantu dari terendah hingga tertinggi diantaranya adalah katakata, tulisan bergambar, rekaman atau audio, film, televisi, pameran, field trip, demonstrasi, sandiwara, benda tiruan dan benda langsung. ${ }^{14}$

Tabel 2. Pengetahuan dan Sikap Sebelum dan Sesudah Diberikan Penyuluhan Gizi

\section{Kelompok}

Perlakuan

- Pengetahuan

Pretest

Postest

Delta Mean \pm SD

- Sikap

Pretest

Postest

Delta Mean \pm SD
Mean \pm SD

$15,1 \pm 3,8$

$18,3 \pm 2,4$

$3,1 \pm 3,6$

$33,0 \pm 3,7$

$37,7 \pm 2,4$

$4,7 \pm 3,3$
Kontrol

- Pengetahuan

Pretest

Postest

Delta Mean \pm SD

- Sikap

Pretest

Postest

Delta Mean \pm SD
$15,8 \pm 2,6$

$18,2 \pm 1,8$

$2,4 \pm 2,2$

$33,1 \pm 3,6$

$34,1 \pm 7,0$

$1,0 \pm 5,2$
Min-max

6,0-20,0

$11,0-20,0$

$27,0-40,0$

$32,0-40,0$

(1) 
dapat memotivasi individu untuk bersikap lebih baik terhadap persoalan kesehatan.9-11 Booklet merupakan media edukasi yang berperan penting dalam peningkatan pengetahuan karena krmampuannya dalam menyampaikan isi pesan atau materi pengetahuan secara efektif. ${ }^{13}$

Edukasi sangat penting untuk meningkatkan pengetahuan ibu, menciptakan motivasi dan persepsi yang baik sebagai landasan mereka dalam menentukan perilaku. ${ }^{16}$ Dalam penelitian ini, sesuai dengan teori reasoned action bahwa intervensi yang diberikan menciptakan suatu lingkungan, persepsi pengetahuan sehingga subyek terpapar dengan informasiinformasi kesehatan khususnya tentang aemia dan kepatuhan ibu hamil dalam mengkonsumsi $\mathrm{Fe}^{16}$. Penelitian ini senada dengan penelitian Hosseini, 2015 di Irak Sleatan pada promosi ASI yang menyatakan bahwa terdapat peningkatan pengetahuan subyek penelitian secara signifikan setelah diberi perlakuan ${ }^{17}$, Lanita et al, 2015 di Yogyakarta yang menyatakan bahwa intervensi dengan booklet pada remaja dapat meningkatkan pengetahuan tentang obesitas ${ }^{18}$ dan Sharpe, 2016 di England pada anak SD dan SMP tentang pengetahuan kesehatan mental ${ }^{19}$. Dalam memilih media intervensi terdapat beberapa pertimbangan tujuan akhir yang ingin dicapai, jumlah sasaran yang ada. Booklet berisi informasi yang lebih lengkap dibandingkan leaflet sehingga memungkinkan subyek membaca detail. Sementara informasi yang diberikan oleh peneliti melalui voice note pada grup WhatsApp merupakan diskripsi yang dapat memperjelas informasi pada booklet. Edukasi dengan media cetak dapat meningkatkan pengetahuan responden, hasil penelitian ini sejalan dengan penelitian Hanasica et al tahun 2020 di Canton, Bosnia terhadap anak sekolah dasar ${ }^{11}$.

Pada penelitian ini, intervensi leaflet juga meningkatkan pengetahuan ibu, meskipun skor peningkatannya lebih rendah dibanding intervensi dengan booklet. Leaflet mempunyai beberapa kelemahan seperti terbatasnya space untuk menuliskan/menyampaikan informasi. Disamping kelemahan tersebut, leaflet praktis digunakan sehari-hari, dapat memberikan penjelasan oral yang telah diberikan sebelumnya, dapat dilipat sehingga mudah dibawa ${ }^{20}$. Pada kedua kelompokperlakuan ini, peningkatan pengetahuan responden disebabkan oleh diterimanya informasi oleh responden selama promosi kesehatan. Informasi tentang anemia selanjutnya akan menambah pemahaman responden tentang anemia sehingga akan meningkatkan pengetahuan mereka tentang anemia. Pendidikan kesehatan merupakan kegiatan-kegiatan yang ditujukan untuk meningkatkan kemampuan seseorang dan membuat keputusan yang tepat sehubungan dengan pemeliharaan kesehatan, sehingga berdasarkan pengalaman diperoleh dapat bermanfaat dalam mempengaruhi kebiasaan, sikap dan pengetahuan seseorang. ${ }^{21}$ Pengetahuan ibu hamil yang baik akan menjadikan ibu memiliki kecenderungan sikap untuk mengonsumsi tablet tambah darah secara rutin dibandingkan dengan ibu hamil yang memiliki pengetahuan kurang. ${ }^{6}$

Hasil penelitian ini juga menunjukkan bahwa pada kedua kelompok perlakuan terdapat peningkatan sikap responden tentang kepatuhan mengkonsumsi $\mathrm{Fe}$, meskipun pada kelompok intervensi booklet peningkatan sikap sebelum dan setelah intervensi lebih tinggi dibanding kelompok leaflet. Sikap merupakan faktor yang ada dalam diri manusia yang dapat mendorong atau menimbulkan perilaku atau tindakan tertentu. Ibu hamil yang memiliki sikap yang baik mengenai pentingnya tablet besi bagi kehamilannya, maka akan memberikan perilaku yang baik pula untuk tetap mengkonsumsi tablet besi sampai 9 bulan kehamilannya. ${ }^{22}$ Ibu hamil dengan pengetahuan yang baik mengenai pentingnya zat besi serta akibat yang ditimbulkan apabila kekurangan zat besi dalam kehamilan akan cenderung membentuk sikap yang positif terhadap dalam mengonsumsi tablet besi sehingga tidak menimbulkan anemia 
pada ibu hamil. ${ }^{15}$ Penelitian Elmika (2018) menjelaskan bahwa dalam meningkatkan pengetahuan dan sikap ibu hamil dalam mengkonsumsi tablet besi adalah dengan memberikan pendidikan kesehatan. ${ }^{21}$ Pendidikan kesehatan atau penyuluhan sangat penting untuk meningkatkan pengetahuan, sikap dan tindakan. Penyuluhan dapat dilakukan secara langsung menggunakan media diskusi seperti leaflet, booklet, lembar balik dan lain-lain.

Hasil penelitian menunjukkan bahwa ada perbedaan bermakna intervensi penyuluhan menggunakan booklet dan leaflet anemia terhadap sikap tentang anemia $(\mathrm{p}=0,002)$. Hal ini mendukung penelitian Safitri (2018) yang menunjukkan terdapat perbedaan sikap antara kelompok perlakuan yang diberi booklet dan kelompok kontrol yang diberi leaflet dengan nilai $\mathrm{p}=0,015 .{ }^{23}$

Pada penelitian ini edukasi diberikan melalui booklet dan leaflet ibu hamil diharapkan dapat mewakili penyampaian informasi mengenai anemia dan mengkonsumsi tablet besi kepada ibu hamil. Booklet lebih dipilih sebagai media edukasi untuk ibu hamil karena dibandingkan dengan media edukasi visual lainnya, seperti poster, informasi yang terdapat di booklet dan leaflet dapat lebih banyak dan terinci. Hasil penelitian ini menunjukkan hasil bahwa informasi yang diberikan melalui booklet dan leaflet ada perbedaan dan terbukti dapat meningkatkan sikap dalam mengonsumsi tablet besi pada ibu hamil.

\section{Kesimpulan}

Pengetahuan ibu tentang anemi dan sikap ibu tentang kepatuhan konsumsi Fe pada kelompok intervensi dengan booklet dan leaflet mengalami peningkatan, namun secara umum booklet efektif dalam meningkatkan pengetahuan dan sikap ibu. Sehingga petugas promosi kesehatan perlu mempertimbangkan penggunaan media cetak tersebut dalam intervensi gizi.

\section{Reference}

1. WHO. Anaemia.

2. Pengembangan Kesehatan Kementerian RI BP. Riset Kesehatan Dasar.

3. DIY DK. Profil Kesehatan DIY Tahun 2019.; 2020.

4. WHO. Prevention of Iron Deficiency Anaemia in Adolescents.

5. Stephen G, Mgongo M, Hashim TH, Katanga J, Stray-pedersen B, Msuya SE. Anaemia in Pregnancy: Prevalence, Risk Factors, and Adverse Perinatal Outcomes in Northern Tanzania. 2018;2018. doi:10.1155/2018/1846280

6. Itsnaini SF, Denok W, Sri S. The Influence of Age, Education, and Knowledge of Consumption of Iron Tablets on Pregnant Women in Maron Public Health Center, District of Probolinggo. In: Open Access under CC BY - SA License. ; :356-363. doi:10.2473/amnt.v2i4.2018.356-363

7. Kamau MW, Mirie W, Kimani S. Compliance with Iron and folic acid supplementation ( IFAS ) and associated factors among pregnant women: results from a cross-sectional study in Kiambu. Published online 2018:1-10.

8. Masyarakat DG. Pedoman Pencegahan Dan Penanggulangan Anemia Pada Remaja Putri Dan Wanita Usia Subur (WUS. Kementerian Kesehatan RI

9. Utara IS, Pustaka T, Muharram I, et al. Pengaruh edukasi mp-asi terhadap peningkatan pengetahuan ibu the effect of breastfeeding complimentary food education on increasing maternal knowledge. 2021;20(2):76-90.

10. Mona D, Azalea FW. Leaflet and pocketbook as an education tool to change level of dental health knowledge. 2018;7(3):760-763. doi:10.15562/bmj.v7i3.1172

11. Hasanica N, Ramic-catak A, Mujezinovic A, Begagic S, Oruc M. The Effectiveness of Leaflets and Posters as a Health Education Method. 2020;32(4):135-139. doi:10.5455/msm.2020.32.135-139 
12. Yuliastuti E. Pengaruh Media Booklet Terhadap Pengetahuan Tentang Pentingnya Makan Sayur Dan Buah Pada Siswa Sekolah Dasar. Poltekkes Kemenkes Yogyakarta

13. Pratiwi YF, Puspitasari DI. Efektivitas penggunaan media booklet terhadap pengetahuan gizi seimbang pada ibu balita gizi kurang di kelurahan semanggi kecamatan pasar kliwon kota surakarta. J Kesehat. 10(1):58-67.

14. S. N. Public Health Sciences Basic Principles. Rineka Cipta; 2003.

15. Wijayanti A. Perbedaan Tingkat Pengetahuan Ibu Hamil Sebelum Dan Setelah Diberikan Penyuluhan Tentang Anemia Gizi Besi Dengan Menggunakan Media Booklet Di Puskesmas Gatak. Skripsi. Universitas Muhammadiyah Surakarta

16. Glanz k, Rimer bk V k. Health Behavior and Health Education:Theory, Research, and Practice. 4th Ed. 4th ed. (Orleans CT, ed.). www.josseybass.com; 2008.

17. Hosseini Z, Gharghani ZG, Mansoori A. Application of the theory of reasoned action to promoting breakfast consumption. Published online 2015.

18. Lanita U, Sudargo T, Huriyati E. dan booklet tentang obesitas pada remaja overweight dan obesitas. 2015;12(1):36-44.

19. Sharpe H, Patalay P, Vostanis P, Belsky J. Use, acceptability and impact of booklets designed to support mental health self - management and help seeking in schools : results of a large randomised controlled trial in England. Eur Child Adolesc Psychiatry. 2017;26(3):315-324. doi:10.1007/s00787-016-0889-3

20. Sustersic M, Gauchet A, Foote A, Bosson J. How best to use and evaluate Patient Information Leaflets given during a consultation: a systematic review of literature reviews. 2017;(July 2016):531-542. doi:10.1111/hex.12487

21. Elmika R, Simbolon D, Yuliantini E. Edukasi Gizi dengan CAMIL Sama Efektif dengan Leaflet dalam Prilaku Pencegahan Anemia pada Ibu Hamil. J Ilmu Dan Teknol Kesehat. 6(1):82-93.

22. Hadar SA. Gambaran Pengetahuan, Sikap Dan Tindakan Ibu Hamil Terhadap Pentingnya Mengkonsumsi Tablet Zat Besi Selama Kehamilannya Di Puskesmas Layang Makassar Tahun 2014. Karya Tulis Ilmiah. Universitas Islam Negeri Alauddin Makassar

23. Safitri D. Pengaruh Pemberian Booklet Terhadap Peningkatan Pengetahuan, Sikap, Dan Dukungan Suami Terhadap ASI Eksklusif Pada Ibu Hamil Di Puskesmas Ngampilan Dan Puskesmas Wirobrajan. Poltekkes Kemenkes Yogyakarta 